\title{
BMJ Global Health From blockchain technology to global health equity: can cryptocurrencies finance universal health coverage?
}

\author{
Brian M Till, ${ }^{1,2,3}$ Alexander W Peters, ${ }^{2,3,4}$ Salim Afshar, ${ }^{2,3}$ John G Meara ${ }^{2,3}$
}

To cite: Till BM, Peters AW, Afshar S, et al. From blockchain technology to global health equity: can cryptocurrencies finance universal health coverage?BMJ Glob Health 2017;2:e000570. doi:10.1136/ bmjgh-2017-000570

Handling editor Soumitra Bhuyan

Received 18 September 2017 Revised 27 October 2017 Accepted 28 October 2017

\section{(a) CrossMark}

${ }^{1}$ Robert Larner College of Medicine, University of Vermont, Burlington, Vermont, USA

${ }^{2}$ Program in Global Surgery and Social Change, Harvard Medical School, Boston, Massachusetts, USA

${ }^{3}$ Department of Plastic and Oral Surgery, Boston Children's Hospital, Boston, Massachusetts, USA ${ }^{4}$ Department of Surgery, Weill Cornell Medical Center, New York, New York, USA

\section{Correspondence to} Dr John G Meara; john.meara@childrens.harvard. edu

\section{ABSTRACT}

Blockchain technology and cryptocurrencies could remake global health financing and usher in an era global health equity and universal health coverage. We outline and provide examples for at least four important ways in which this potential disruption of traditional global health funding mechanisms could occur: universal access to financing through direct transactions without third parties; novel new multilateral financing mechanisms; increased security and reduced fraud and corruption; and the opportunity for open markets for healthcare data that drive discovery and innovation. We see these issues as a paramount to the delivery of healthcare worldwide and relevant for payers and providers of healthcare at state, national and global levels; for government and non-governmental organisations; and for global aid organisations, including the WHO, International Monetary Fund and World Bank Group.

\section{INTRODUCTION}

In 1978, leaders from around the world met in Alma-Ata. ${ }^{1}$ They declared health as a fundamental human right and made clear that the realisation of health equity was a 'most important worldwide social goal.' Despite profound investment and effort, realising this vision has eluded policymakers for nearly 40 years. Towards this aim, the WHO has called for access to universal health coverage (UHC), ${ }^{2}$ and World Bank president Dr Jim Kim made clear his own institution's support for UHC, arguing before the World Health Assembly in May 2013 that access to care was foundational to ending poverty. ${ }^{3}$ Achieving such health equity and universal access to healthcare is dependent on equitable access to capital markets; allowing nation-states, municipalities, hospitals and clinics access to the capital flows to develop infrastructure, workforce and supply chains. In turn, accessing such capital is dependent on improved transparency, such that investors can see how, when and where funds are deployed, and exactly what returns have been achieved as a result of this investment. This level of transparency remains impossible under the prevailing system of

\section{Key questions}

- Cryptocurrencies could enable universal access to financing mechanisms by removing third-party financial intermediaries and offering transparent, secure and accountable means for global health financing.

- Blockchain technology could usher in a new era of multilateral financing mechanisms, for example, through the use of smart contracts for health system development.

- A blockchain-based financing system could reduce fraud and corruption in global health development while accelerating necessary transactions through secure, immutable ledgers.

- Blockchain technology could create new capital markets for healthcare data, engaging patients, hospitals, governments, researchers and others in an open market that could drive down costs and accelerate discovery and innovation.

monetary exchange. The weaknesses of this current paradigm beg the question: What if strategy, process, outcome and funding could all be inextricably linked?

Blockchain, the technology underlying Bitcoin, Ethereum and countless other cryptocurrencies, is built atop a network that makes trusted, secure, immutable and interoperable records of every transaction. Moreover, it makes this record available in every corner of the globe. This technology is already being adopted by a variety of industries, including banking, minerals and mining, and food procurement. ${ }^{45}$ While others have written about the power of blockchain to revolutionise health information technology ${ }^{6}$ and payment models, ${ }^{7}$ in this paper, we outline the capacity for blockchain technology to revolutionise global health by enabling universal access to financing, new multilateral financing mechanisms and smart contracts, data markets, and new standards for payments and reimbursement, thus empowering countries, institutions and consumers. 


\section{CURRENT PROBLEMS FACING GLOBAL HEALTHCARE FINANCE}

Today, health systems in low and middle-income countries (LMIC) remain severely underfunded and suffer from limited access to capital markets. This, alongside weaknesses in workforce and infrastructure, represents the most fundamental challenges faced by these health systems. In 2014, per capita health spending in low-income countries (LIC) was $\$ 120$ as compared with $\$ 5221$ in high-income countries (HIC). ${ }^{8}$ In the current financial paradigm, per capita health spending in LICs is projected to rise to only $\$ 195$ by $2040 .{ }^{9}$ Workforce creation and sustainability are dependent on capital flows; without more equitable access to capital and healthcare investments in LMICs there can be no substantial movement towards UHC and health equity.

There are many reasons why potential funders have historically shied away from investment in low and middle-income health systems. First, potential investors-both traditional donor agencies and sources of private, for profit investment-often have insufficient data about the quality of care and management of institutions in which they could potentially invest. Second, such investments have often been inefficient, if not wasteful, and unable to yield meaningful health impacts. These upfront data gaps, operational inefficiencies, and inadequate monitoring and evaluation frameworks have limited capital flow into healthcare in LMICs because the return on investment-either financial or socialhas been largely impossible to track. Blockchain has the potential to offer meaningful solutions to each of these challenges.

\section{A MOVE TOWARDS UNIVERSAL ACCESS TO FINANCING}

In its June 2017 report on FinTech, the International Monetary Fund (IMF) found that emerging technologies are likely to improve cross-border payments with cheaper, faster and safer options, and blur boundaries between markets, intermediaries and financial service providers. ${ }^{10}$ The emergence of Bitcoin and other cryptocurrencies has created a new era in global finance in which a global-currency-for-all will promote universal access to financing. Cryptocurrencies that use blockchain are based on the concept of an ever growing, immutable, distributed ledger that can provide a secure, transparent, global currency with the potential to fundamentally alter global access to finance. Born out of the 2008 financial crisis, cryptocurrencies remove third-party institutions from finance and directly enable parties to pay and receive assets over a trusted peer-to-peer network.

This represents a significant paradigm shift towards creating global health and financial equity through universal access to financing. First, Bitcoin's value is in its transparency and security. The system minimises fraud and prevents counterfeiting compared with current financing mechanisms, giving financial credibility to anyone who has funds. In such a way, cryptocurrency has the capacity to dissolve barriers to world markets by enabling everyone-from the world's poorest to its wealthiest, individuals and institutions-to accumulate wealth in a secure transnational currency and to become trusted payers.

Second, by removing financial institutions as thirdparty intermediaries, cryptocurrencies using blockchain ledgers stand to further promote global financial equity by allowing those previously without access to trusted financial institutions-due to poverty, instability or corruption, for example - to bypass the hurdles and overcome the costs of accessing financial institutions. Unlike third-party financial intermediaries with potentially high fees and long processing delays, cryptocurrencies offer faster payments, remittances with minimal transaction cost and increased verifiability that money arrives where it is sent (figure 1). The cost and speed of such a blockchain will be highly dependent on what is developed in coming months and years. In terms of savings, it is worth considering the World Food Program's pilot of blockchain financial transfers to 10000 Syrian refugees, which reduced transfer fees from $1.5 \%$ to effectively zero, and is predicted to bring transaction costs from $\$ 150000$ per month to $\$ 1.50$ after full scale-up. ${ }^{11}$ As barriers to financing disappear, the cryptocurrency framework will open new avenues for countries, institutions and individuals to contribute through direct financing to other countries, institutions and individuals with full transparency, security and accountability.

\section{A NEW ERA OF MULTILATERAL FINANCING MECHANISMS}

Typically, a proposed cryptocurrency transaction relies on the verification of several data points to be executed. The proposed buyer must have the currency available to transfer, the recipient must be validated on the network, and the money designated to be moved must not be involved in any other transactions. A transaction occurs only after a member of the network verifies this information, and more than half of the other network nodes endorse this work. By design, cryptocurrencies protect against duplicate or counterfeit transactions. Such a system enables complex, automated transactions, and recently, the cryptocurrency Ethereum began to employ sophisticated 'Smart Contracts' (figure 2). In these transactions, conditions must be satisfied before a transaction can be executed (ie, a certain amount of time may be required to elapse, or a certain number of shareholders may need to sign off on a transaction). Such smart contracts can similarly be tailored to healthcare and to healthcare system development in a variety of ways.

\section{Traditional funding}

Smart contracts can revolutionise traditional grants and funding from legacy donor agencies such as the IMF, World Bank, United States Agency for International Development, and Department for International Development. In recent years, the practice of resultsbased financing has gained traction in international 


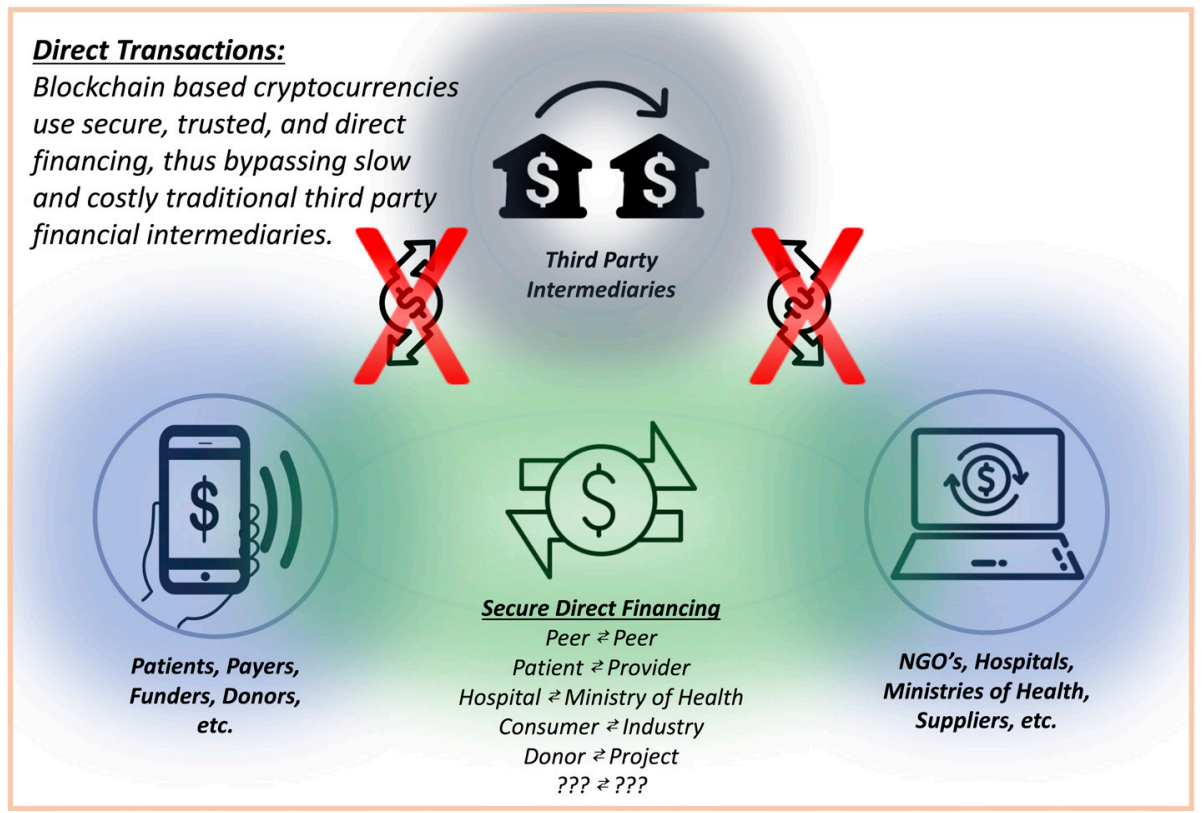

Figure 1 Direct transactions. NGO, non-governmental organisation.

development. ${ }^{12}$ Such financing schemes offer local policymakers sovereignty over how money should be spent, and offer continued or increased funding if and when preset goals are achieved. Verifying such results, however, remains exceedingly costly, ${ }^{13}$ often requiring on the ground verification by the grant makers. In addition, outcome measures must be quite broad and simplistic (eg, the percentage of women of unknown HIV status checked at annual visits, or percentage of women in the third phase of labour who receive tocolytics). Even still, results remain largely falsifiable with scarce accountability. A blockchain in healthcare development could use unique identifiers for equipment, supplies, patient care, lab results, combined with time and geolocation stamps. It could quickly and verifiably demonstrate exactly what services are performed and what outcomes are achieved. Similarly, at an institutional level, profit and loss can be monitored in real time, both by local and system level administrators, as well as by grant funders. A smart contract could release additional funding as verifiable outcomes are reached or development goals are met.

\section{New funding streams}

More importantly, smart contract blockchains for healthcare will create new funding and capital streams and potentially bring new funders into global health delivery. For example, the rise of social impact bonds and development impact bonds in recent years, which have been employed in a variety of forms from reducing asthma-related in paediatric emergency department

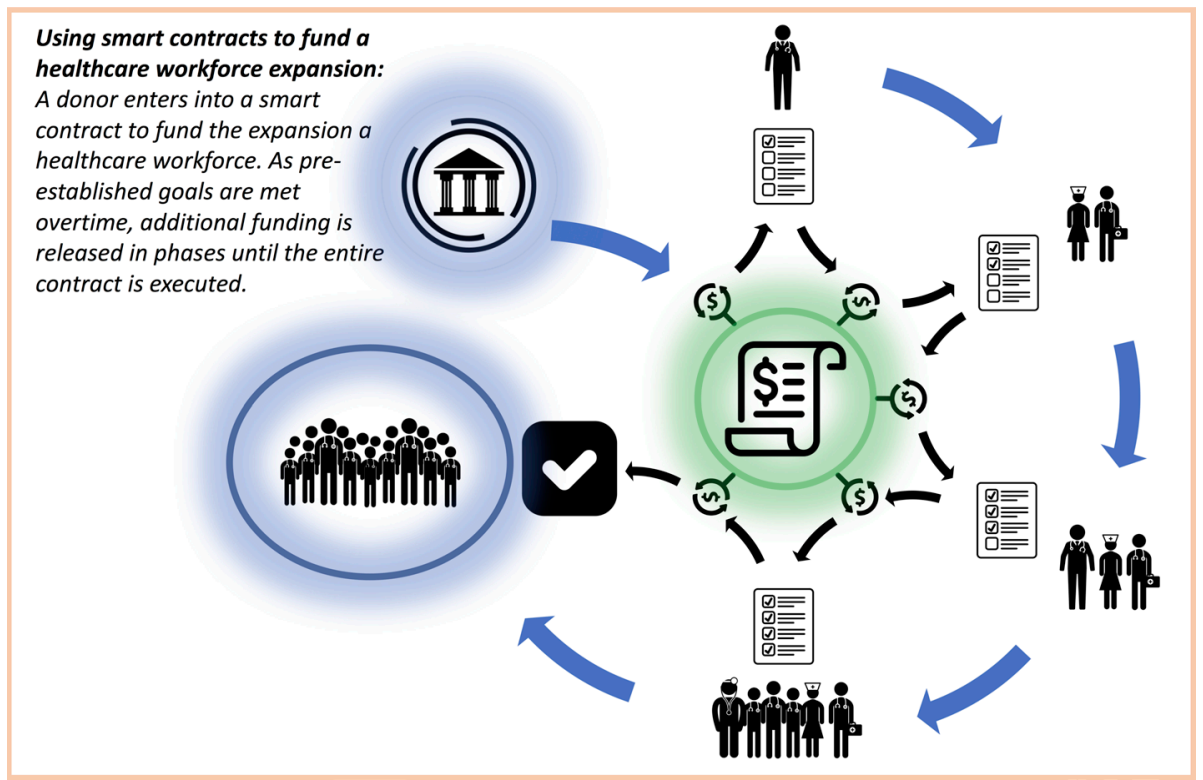

Figure 2 Smart contracts. 
visits ${ }^{14}$ to improving access to education for girls in rural India, ${ }^{15}$ illustrates a broad market interest in investments intended to deliver social goods, reduce costs and bridge global health inequity gaps. These bonds have the potential to bring new funders into global health and development, but have seen challenges scaling with investors because of difficult measuring impact and time gaps in return on investment. ${ }^{16}$ Smart contracts built on blockchain currencies like Ethereum are well suited to facilitate social and development impact bonds because they can automate social outcome-based funding and add new accountability to development financing. Similarly, the World Bank has revealed plans to explore how blockchain can facilitate a mobile phone-based bond issuance program in Kenya ${ }^{16}$ called M-Akiba aimed at promoting savings and investment by Kenyans. ${ }^{17}$

These new mechanisms represent only a few ways in which smart contracts on blockchain cryptocurrencies could develop new accountable funding streams and transform global health financing. With advancements in interoperability, blockchain smart contracts could tie the purchase of large capital items to registration on parallel linked supply chain and inventory management systems, preventing fraud and corruption by ensuring that grant funds go to the intended capital goods purchases and those goods are delivered to the intended recipients; and, it is likely that this emerging technology will only make multistakeholder-funded projects easier to execute and monitor with trusted accountability as funding rules are prebuilt into smart contracts at the outset. Blockchain-based systems could pave new paths for transnational healthcare capital markets, decentralised venture capital projects, distributed funding, microfinance and microinsurance across the globe in healthcare development.

\section{SECURE, STANDARDISED AND IMMUTABLE TRANSACTIONS}

In addition, blockchain has the potential to revolutionise healthcare financial transactions, ranging from insurance verifications, to payment methods, to transnationally crowdsourced global funding. Under current data mechanisms, transactional processes are slowed by data reconciliation and user verification, which leads to significant delays and waste for all parties involved. Furthermore, the inability to interrogate and cross-verify health data under the current system opens up an abundance of opportunities for fraud, with some estimating that $7.29 \%$ (US $\$ 420$ billion) of global health expenditure is lost to fraud or error. ${ }^{18}$

Blockchain technology, however, is designed to create an immutable ledger which can serve as a permanent record of all transactions-resistant to tampering, hacking or rewriting. As a result, purpose-built data analytics can be applied to the chain in order to identify fraudulent activity while simultaneously accelerating transactions. For example, today electronic prescriptions are directed to specific institutions, making it impossible to reconcile all records of pharmacies and electronic health records across institutions. This results in both waste and fraudulent claims. With an interoperable blockchain-based ledger, each institution could see all the events surrounding a particular prescription-from the writing to filling to refilling-removing all potentials for duplicity from the process.

Similarly, claims processing could be tied to actual generation of patient data, making fraudulent claims that lack associated results more difficult. As health information moves towards an interoperable health blockchain, or 'Electronic Health Chain', an increasing number of currently siloed data sets will be linked, making fraudulent activity more challenging and the ability to detect it and other unusual activity less challenging.

Countries that have already created biometric identification databases are well positioned to leverage blockchain technology in healthcare. For example, in 2016, India implemented the Aadhaar Card, a database that contains photographs and basic demographic and biometric data of over 1.167 billion Indian citizens. Using this verifiable, digital proof of identity, blockchain applications will be able to ensure that financial transfers and the delivery of goods and services reach the intended recipients and consumers, by creating blocks that contain these unique data (such as an iris scan) upon successful receipt of goods or services. With global trends towards creating similar centralised ID systems, the feasibility of using blockchain technology to build smart contracts, direct funding and prevent fraud becomes a reality.

\section{CAPITALISING ON HEALTH DATA AT EVERY LEVEL}

Today, commodities and financial products are traded in an open and free market reaching around the world. Futures for oil, corn, precious metals and even carbon dioxide are traded by banks and individuals in all corners of the globe. With blockchain, the creation of a comparably open and transparent health data network is possible; and the creation of such a market offers the potential for both individuals and health systems to monetise the data they accrue (figure 3). Such health data, combining data from medical records, wearable devices, pharmacies and, increasingly, genetic and genomic data, stand to tell us more about human health than any major trial or series could. Efficacy of competing treatment algorithms for patients with cancer, and their likelihood of success based on factors not currently woven into treatment plans; implications of partial medication compliance on long-term health outcomes; and the optimised management of chronic diseases across wildly different populations, all stand to be elucidated by such data. Presumably, the value of such data will ebb and flow over time, as more is learnt and better medications and treatment plans are optimised for various diseases and populations. Data for patients with Alzheimer's today, for instance, are far more valuable than it would have been 50 years ago, while data for thyroid disorders are far less valuable than 


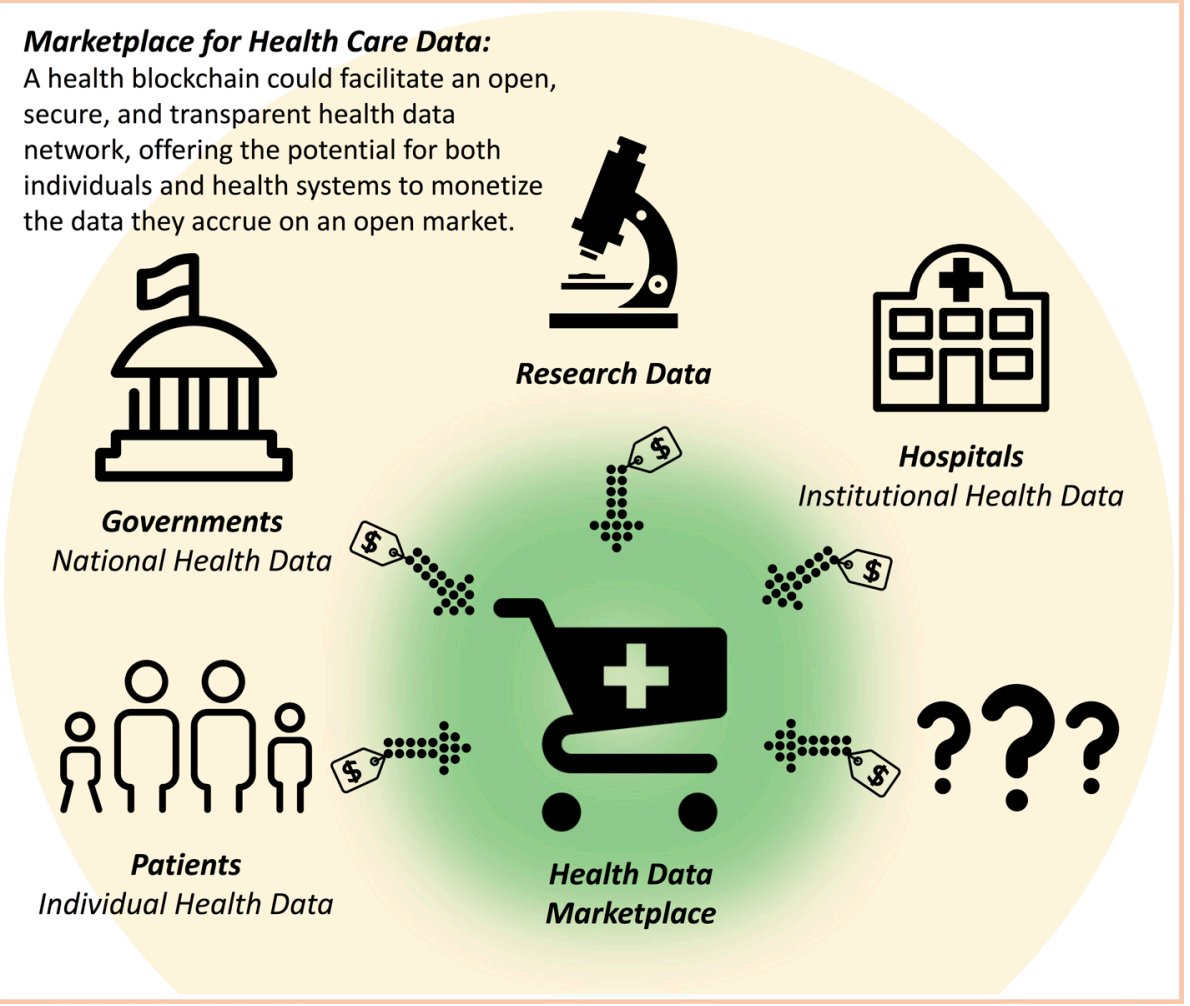

Figure 3 Healthcare data marketplace.

it might have been in the 1920s. An open market would reflect the current value of health data, based on burden of disease and ongoing research. Moreover, blockchain creates the opportunity for medical information to remain the property of the patient, thus allowing an individual to opt in or out of given research studies. This can be accomplished by using the above reference biometric data as a kind of private key, requiring researchers to gain approval and ascent from the patients before using their anonymised health data.

Moving health data from its current, protected status onto open, anonymised public ledgers will require a reorientation of thought and law in many countries. In the USA, for instance, the Health Information Portability and Accountability Act poses a significant hurdle. Notably, the use of mathematically derived pseudonyms is likely to run afoul of the regulation. ${ }^{19}$ It will be imperative for policymakers in these countries to create space for information to move legally from its current storage on fragmented, centralised, identifiable health records which continue to provide rich targets for hacking and extortion, onto encrypted blockchains. ${ }^{20}$

For LMIC governments, this type of data ownership, control and marketisation of health information could incentivise or promote investments in health system strengthening in exchange for access to national data. Industry could expand beyond their limited 'corporate social responsibility' budgets for LMIC investments and make real market-based decisions with the knowledge that smart contracts and predetermined data flows would correspond to their capital investments in specific health sectors or even more global health system investments at a national scale. Furthermore, as LMICs capitalise on their national health data for research and innovation, it is likely to drive down the value of data in HICs and create a more equitable global market for health data. These market forces will drive down the costs of wearable devices, cellphones and other means for data collection, health monitoring and evaluation as research and innovation turns to LMICs, subsequently expanding LMIC access to monitoring and evaluation methods and giving them new focal points to target cost- effective national and local health interventions.

\section{CONCLUSION}

UHC and global health equity will not be achieved without first establishing more equitable access to capital markets and financing at all levels, from nation-state to patient-consumer. Innovation in cryptocurrency and blockchain technology have the potential to dissolve transnational financing barriers and address issues facing equitable capital access including ease of use, accountability, transparency, monitoring and evaluation, corruption and fraud. For blockchain to reach its full potential and help move the world towards health equity, the global health community and the global financial community must work together to help guide-not force, stifle or oppress-this process. Openness and accessibility are what make blockchain so unique and transformative.

To be clear, blockchain does not represent a silver bullet. There are many obstacles to be overcome before 
the potential highlighted here can be realised. First, as mentioned above, achieving appropriate regulatory guidelines for both financial transaction and medical information assimilation onto blockchain is imperative for legacy organisations to move more aggressively into this space. Second, it is imperative that advances in blockchain technology not be limited to large, private companies, but rather remain as a fundamentally open-source technology. Third, the very size of health data poolsparticularly imaging files-limits the feasibility of entire health records living on a blockchain. Innovation into data management, such that tags linking full files to the chronological record built into the blockchain, will be imperative without a revolution of computational power. Finally, LMICs will also need assistance to realise the full potential of blockchain technology. Improved internet access is a first step-in Africa now, internet access stands at $2 \%-30 \%{ }^{21}$ - smart device penetration, education about blockchain and its uses, and interoperability in healthcare technology will all play pivotal roles in accelerating this process. For their parts, governments, healthcare organisations and consumers will need to become more familiar with how cryptocurrencies and the blockchain work. Opening cryptocurrency accounts, verifying your identity, experiencing its security and transferring assets into these cryptocurrencies are all prerequisite steps towards participating in cryptocurrency capital markets and joining this next technological, financial and global health revolution.

Correction notice This article has been corrected since it first published. The middle initial of the last author is missing. His correct name is John G Meara and he should be cited as Meara JG.

Contributors All authors contributed to the manuscript in its entirety from conception, design, analysis and composition.

Competing interests None declared.

Provenance and peer review Not commissioned; externally peer reviewed.

Open Access This is an Open Access article distributed in accordance with the Creative Commons Attribution Non Commercial (CC BY-NC 4.0) license, which permits others to distribute, remix, adapt, build upon this work non-commercially, and license their derivative works on different terms, provided the original work is properly cited and the use is non-commercial. See: http://creativecommons.org/ licenses/by-nc/4.0/

(c) Article author(s) (or their employer(s) unless otherwise stated in the text of the article) 2017. All rights reserved. No commercial use is permitted unless otherwise expressly granted.

\section{REFERENCES}

1. World Health Organization. Declaration of Alma-At: International Conference on Primary Health Care, 1978.

2. World Health Organization. Universal Health Coverage, Sustainbale Development Goal \#3. http://www.who.int/universal_health_ coverage/en/ (accessed 16 Sep 2017).

3. Kim JY. Poverty Health and the Human Future, 2013.

4. Casey M. Global Supply Chains Are About to Get Better, Thanks to Blockchain. https://hbr.org/2017/03/global-supply-chains-are-aboutto-get-better-thanks-to-blockchain (accessed18 Oct 2017).

5. Niforos M, Ramachandran V. Blockchain: Opportunities for Private Enterprises in Emerging Markets. Washington, DC: International Finance Corporation, 2017.

6. Yip K. Blockchain and Alternative Payment Models: A look at where blockchain technology can be implemened to further APM goals. 2017 https://www.healthit.gov/sites/default/files/15-54-kyip_ blockchainapms_080816.pdf (accessed 18 Oct 2017).

7. Linn L, Koo M. Blockchain For Health Data and Its Potential Use in Health IT and Health Care Related Research. https://www.healthit. gov/sites/default/files/11-74-ablockchainforhealthcare.pdf (accessed 18 Oct 2017).

8. The World Bank. Health Expenditure Per Capita. https://data. worldbank.org/indicator/SH.XPD.PCAP (accessed 16 Sep 2017).

9. Dieleman JL, Campbell M, Chapin A, et al. Future and potential spending on health 2015-40: development assistance for health, and government, prepaid private, and out-of-pocket health spending in 184 countries. Lancet 2017;389:2005-30.

10. Fintech and Financial Services: Initial Considerations. The International Monitary Fund, 2017.

11. Pisa M, Juden M. Blockchain and Economic Development: Hype vs. Reality. Center for Global Development Policy Paper 107, 2017.

12. Africa Health Forum Finance and Capacity fo Results The World Bank. Results-Based Financing for Health. 2013 http://siteresources. worldbank.org/INTAFRICA/Resources/AHF-results-based-financing. pdf (accessed 17 Sep 2017).

13. Verger P. Verification in Results-Based Financing World Bank Group, 2016.

14. Crowley DM. The role of social impact bonds in pediatric health care. Pediatrics 2014;134:e331-e333.

15. Perakis R. Center fior Global Development. First Development Impact Bond Is Launched. https://www.cgdev.org/blog/firstdevelopment-impact-bond-launched (accessed 16 Sep 2017).

16. Triggerise. Technology Opens up a Whole New World of Opportunities for Social Impact Bonds. $2017 \mathrm{http}: / /$ triggerise.org/ technology-opens-up-a-whole-new-world-of-opportunities-forsocial-impact-bonds/ (accessed 16 Sep 2017).

17. Kamau M. Kenyans raise Sh117.6 million through purchase of M-Akiba bond. $2017 \mathrm{https} / / /$ www.standardmedia.co.ke/business/ article/2001234967/kenyans-raise-sh117-6-million-throughpurchase-of-m-akiba-bond (accessed 16 Sep 2017)

18. The financial cost of healthcare fraud. What data from around the world shows. Unversity of Portsmouth, Centre for Count Fraud Studies, 2015.

19. Kelly J. Bitcoin for Care: Healthcare Hopping on the Blockchain. http://www.wahcnews.com/articles/07-2017/wa-jkelly-0717.php (accessed 18 Oct 2017).

20. Wagstaff K. Big Paydays Force Hospitals to Prepare for Ransomware Attacks. NBC News. 2016.

21. Goussard H. Digital currency could spark African financial revolution. 2017 https://www.howwemadeitinafrica.com/digital-currency-sparkafrican-financial-revolution/59387/ (accessed 18 Sep 2017). 


\section{Correction: From blockchain technology to global health equity: can cryptocurrencies finance universal health coverage?}

Till BM, Peters AW, Afshar S, et al. From blockchain technology to global health equity: can cryptocurrencies finance universal health coverage? BMJ Glob Health 2017;2:e000570.

This article has been corrected since it first published. The middle initial of the last author is missing. His correct name is John G Meara and he should be cited as Meara JG.

Open Access This is an Open Access article distributed in accordance with the Creative Commons Attribution Non Commercial (CC BY-NC 4.0) license, which permits others to distribute, remix, adapt, build upon this work non-commercially, and license their derivative works on different terms, provided the original work is properly cited and the use is non-commercial. See: http://creativecommons.org/icenses/by-nc/4.0/

(C) Article author(s) (or their employer(s) unless otherwise stated in the text of the article) 2017. All rights reserved. No commercial use is permitted unless otherwise expressly granted.

BMJ Glob Health 2017;2:e000570corr1. doi:10.1136/bmjgh-2017-000570corr1

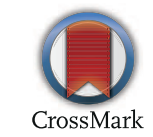

